\title{
Angiotensin-converting enzyme gene I/D dimorphism does not play a major role in the susceptibility of Malaysian systemic lupus erythematosus patients
}

\author{
L.-H. Lian, T.-P. Lau, A.-S. Ching and K.-H. Chua \\ Department of Molecular Medicine, Faculty of Medicine, \\ University of Malaya, Kuala Lumpur, Malaysia \\ Corresponding author: L.-H. Lian \\ E-mail:1hlian@ummc.edu.my
}

Genet. Mol. Res. 11 (2): 863-871 (2012)

Received March 18, 2011

Accepted July 30, 2011

Published April 10, 2012

DOI http://dx.doi.org/10.4238/2012.April.10.2

\begin{abstract}
Systemic lupus erythematosus (SLE) is an autoimmune disease that causes systemic damage, involving auto-reactive antibodies and over-deposition of immune complexes. Susceptibility to SLE is believed to be multifactorial, and genetics is one of the proven etiological factors; it can affect SLE development, severity and prognosis. We investigated a possible association between the angiotensin-converting enzyme gene and susceptibility to SLE in the Malaysian population. PCR was employed for the determination of I/D dimorphism of this gene. The I allele was more frequent than the D allele in both the SLE patients $(\mathrm{N}=170)$ and healthy controls $(\mathrm{N}=$ 190). However, there was no significant difference in the distribution of these two alleles between both groups studied $\left(\chi^{2}=0.284, \mathrm{P}>0.05\right)$. Interestingly, the DD homozygous genotype scored notably higher in the healthy control group $\left(\chi^{2}=7.568, \mathrm{P}<0.05\right)$, while the ID heterozygote was observed to be significantly associated with $\operatorname{SLE}\left(\chi^{2}=11.143, \mathrm{P}<\right.$ $0.05)$. In conclusion, with respect to the Malaysian population, the DD
\end{abstract}


genotype might play a protective role in the development of SLE while in contrast, those who carry the ID genotype might be at potential risk for onset of this disease.

Key words: ACE; SLE; Polymorphism; Malaysia

\section{INTRODUCTION}

Systemic lupus erythematosus (SLE) is a characteristic systemic autoimmune disease, where the presence of auto-reactive antibodies against the body's self-antigens results in the over-deposition of immune complexes (Wallace and Hahn, 1997). There are a range of auto-antibodies that have been found to be typical in SLE, namely the antinuclear antibodies, antibodies to native DNA (anti-DNA) and antibodies to Smith nuclear antigens (anti-Sm) (Tan et al., 1982; Kumar et al., 2007). In Malaysia, the overall prevalence rate of SLE is 43 per 100,000 persons with substantial differences among the three main ethnic groups in the local population, i.e., the Chinese (46/100,000 persons), the Malays (26/100,000 persons) and the Indians (12/100,000 persons) (Wang et al., 1997). SLE is a disease with strict gender bias, where its occurrence is more common in women than men with a ratio of 9:1 (Kumar et al., 2007). As in Malaysia, the female to male ratio is approximately 12:1 (Wang et al., 1997). These statistics have evidently shown the important roles of genetic, hormonal and environmental factors in determining the occurrence of SLE (Wallace and Hahn, 1997).

In general, the pathophysiologic features of SLE are the presence of auto-antibodies in an excessive amount and the deposition of immune complexes in various tissues and organs (Wallace and Hahn, 1997). These are due to the over-production of auto-antibodies as well as failure in the clearance of immune complexes. The over-deposition of immune complexes will activate the complement system, which subsequently leads to tissue damage (Wallace and Hahn, 1997). As a result, the common clinical manifestations in SLE patients are the sequelae of tissue inflammation and damage, i.e., malar rash, proteinuria, arthritis, photosensitivity, oral ulcers, psychosis, pleuritis, and nephritis (Wang et al., 1997).

Typically, the onset of SLE is triggered by the presence of a set of susceptibility genes and environmental stimuli (Wallace and Hahn, 1997). Some of the important target genes such as C4, C1q, CTLA-4, IL-6, IL-1, RANTES-28, and SDF-1 have been studied previously in the Malaysian population (Puah et al., 2007; Chew et al., 2008; Chua et al., 2009a,b, 2010; Lian et al., 2011); however, most of them were found to have no major significant association with SLE susceptibility. Hence in this study, we aimed to target and investigate the distribution of the angiotensin-converting enzyme (ACE) gene insertion/deletion (I/D) dimorphism and its potential association to the susceptibility of SLE.

Broadly, the ACE gene, which consists of 26 exons and 25 introns, is located on the q arm of chromosome 17 (17q23.3). There are two isoforms of ACE present in our body, i.e., the circulating form and the membrane-bound enzyme (Kim et al., 2001). The ACE is expressed in several organs such as the kidneys, heart, testes, lungs, and vascular endothelium (Pullmann Jr. et al., 1999). Physiologically, ACE plays a vital role in the renin-angiotensin system (RAS) and kallikrein-kininogen system (Pullmann Jr. et al., 1999). In the RAS, ACE catalyzes the conversion of angiotensin I to angiotensin II. The angiotensin II is a potent vasoconstrictor that mainly affects the contraction of vascular smooth muscle. Moreover, it is also essential in the 
adhesion and aggregation of platelets, adhesion of monocytes, as well as the proliferation of smooth muscle (Kaufman et al., 2001). In consequence of its crucial role in the RAS, the ACE may contribute to vascular damage, especially in kidneys in SLE patients.

The ACE I/D dimorphism involves the insertion or deletion of an Alu repeat sequence of $287 \mathrm{bp}$ in the intron 6 of the ACE gene. Thus, there are two alleles present, i.e., the I and D alleles, based on the presence or absence of this short repeat sequence, respectively. In parallel, there are three genotypes being observed, namely the II homozygote, ID heterozygote and DD homozygote (Kim et al., 2001). Overall in this study, we focus on the investigation of the potential association between the ACE I/D dimorphism and susceptibility of SLE in the Malaysian population. We also looked at the ACE I/D of the Malaysian population in relation to the observed frequencies in other ethnicities across the globe. To the best of our knowledge, this is the first study of its kind carried out in Malaysia.

\section{MATERIAL AND METHODS}

Sample collection was only carried out after obtaining the approval from the University of Malaya Ethics Committee Review Board (Ethics Approval 380.6). All of the blood samples were collected from volunteers with informed consent at University of Malaya Medical Centre (UMMC), Kuala Lumpur, Malaysia. There were a total of 170 SLE patients and 190 healthy controls recruited for this study. All SLE patients included in this study had fulfilled the 1982 revised American College of Rheumatology (ACR) criteria for the accurate diagnosis of SLE (Tan et al., 1982).

In general, genomic DNA was extracted from the collected peripheral blood samples using a conventional DNA extraction method (Chua et al., 2009c). The concentration and purity of the isolated genomic DNA were measured and determined via spectrophotometry.

In terms of the ACE gene I/D dimorphism determination, a conventional PCR was carried out, followed by a confirmatory PCR as described in previous studies (Shanmugam et al., 1993; Uhm et al., 2002). In silico PCR as described previously was carried out prior to actual PCR evaluation to make sure the primers used are targeted to the correct loci (Teh et al., 2010; Thong et al., 2011). The forward and reverse primers are 5'-CTG GAG ACC ACT CCC ATC CTT TCT-3' and 5'-GAT GTG GCC ATC ACA TTC GTC AGA T-3', respectively. The PCR conditions were set at $94^{\circ} \mathrm{C}$ for $5 \min (1 \mathrm{cycle}) ; 94^{\circ} \mathrm{C}$ for $1 \mathrm{~min}, 58^{\circ} \mathrm{C}$ for $1 \mathrm{~min}$ and $72^{\circ} \mathrm{C}$ for $2 \mathrm{~min}$ ( 30 cycles) and $72^{\circ} \mathrm{C}$ for $7 \mathrm{~min}$ ( 1 cycle) according to Uhm et al. (2002).

Generally, the three distinct genotypes of the ACE gene, i.e., the II homozygous, DD homozygous and ID heterozygous, can be differentiated after the initial conventional PCR. However, amplification of the I allele would be suppressed in an ID heterozygote, which might lead to mistyping as DD homozygote. The exact mechanism behind this mistyping error still remains unknown (Shanmugam et al., 1993). Hence, a confirmatory PCR needs to be performed in order to accurately genotype the ID heterozygous and DD homozygous, as previously described by Shanmugam et al. (1993).

In the confirmatory PCR, the reverse primer remains the same as in the conventional PCR with the sequence as stated previously, while the forward primer is replaced with a new insertion-specific primer (5'-TTT GAG ACG GAG TCT CGC TC-3'). The PCR conditions were also further modified based on the study done by Shanmugam et al. (1993) to accurately obtain the results. Overall, the PCR conditions were set at $94^{\circ} \mathrm{C}$ for $5 \mathrm{~min}(1 \mathrm{cycle}) ; 94^{\circ} \mathrm{C}$ for $1 \mathrm{~min}$, 
$60^{\circ} \mathrm{C}$ for $1 \mathrm{~min}, 72^{\circ} \mathrm{C}$ for $2 \min (30$ cycles $)$ and $72^{\circ} \mathrm{C}$ for $7 \mathrm{~min}(1 \mathrm{cycle})$. The PCR amplicons of both conventional and confirmatory PCR were electrophoresed on a $\%(w / v)$ agarose gel.

Statistical analysis of the allelic and genotypic frequencies was carried out after obtaining the results. Chi-square $\left(\chi^{2}\right)$, probability and odds ratio (OR) with $95 \%$ confidence interval $(95 \% \mathrm{CI})$ values were determined in this context (McPherson, 2001; Armitage et al., 2002). The differences were significant at $\mathrm{P}<0.05$.

\section{RESULTS AND DISCUSSION}

In this study, all the three genotypes of this $\mathrm{ACE}$ gene dimorphism were observed in our local population. Figure 1 (lanes 2-4) shows the banding patterns of these genotypes after the conventional PCR. Post-amplification, the II homozygote was represented by a 490-bp fragment, while the DD homozygote was $190 \mathrm{bp}$ in length. On the other hand, the ID heterozygote was denoted by the presence of both 490- and 190-bp fragments. Subsequently, only the samples, which were genotyped as DD homozygote, were subjected to another confirmatory PCR to further confirm the genotypes.

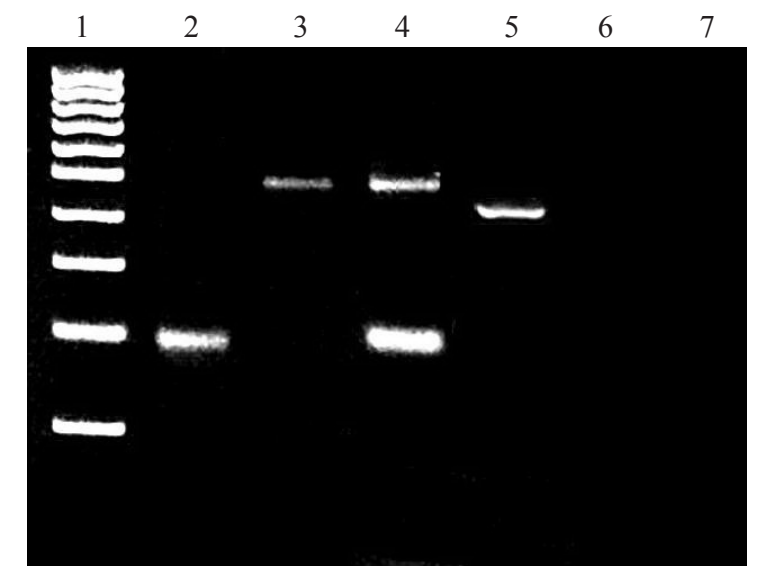

Figure 1. ACE gene I/D polymorphism amplicons on an agarose gel after conventional and confirmatory PCR methods. Lane 1 = 100-bp molecular weight marker; lane 2 = DD homozygous genotype (190 bp); lane 3 = II homozygous genotype (490 bp); lane $4=$ ID heterozygous genotype ( $490+190 \mathrm{bp})$; lane $5=$ ID heterozygous genotype (408 bp); lane $6=$ DD homozygous genotype; lane $7=$ DNA blank. Genotyping of ACE gene I/D polymorphisms by conventional PCR (lanes 2-4); a second PCR was carried out for further confirmation of ID and DD genotypes (lanes 5 and 6).

Both conventional and confirmatory PCRs were carried out in sequence in order to eliminate the possibility of mistyping of the ID heterozygous as DD homozygous. This is due to the fact that the amplification of the I allele tends to be suppressed and masked by the $\mathrm{D}$ allele. The conventional PCR for the analysis of ACE I/D dimorphism was first designed by Rigat and his researchers in 1992. However, the phenomenon of mistyping has been estimated to occur at a frequency of approximately 5 to $10 \%$, due to the higher amplification rate of the relatively shorter sequence of the D allele (190 bp) compared to the I allele (490 bp), especially in the heterozygous state (Chiang et al., 1998; Pfohl et al., 1999; Kim et al., 2001). Hence, a confirmatory PCR was required to counter this problem (Chiang et al., 1998). In the 
confirmatory PCR, a new insertion-specific primer, which only anneals specifically to the 5 '-end of the insertion sequence in the I allele, was used as the forward primer and a 408-bp amplified fragment was produced (Shanmugam et al., 1993). In this context, the D allele will not be amplified since there is an absence of annealing site for this new primer. As a result, the 'true' ID heterozygote can be differentiated from the mistyped DD homozygote. Figure 1 (lanes 5,6) reveals the actual results observed for both ID heterozygote and DD homozygote in a confirmatory PCR. The presence of a 408-bp amplified product indicates the ID heterozygous state, whereas an absence of any band observed denotes the DD homozygote.

Both Tables 1 and 2 report the allelic and genotypic distribution of the ACE gene dimorphism in the Malaysian population, respectively. The I allele was found to be at a higher frequency compared to the D allele in both SLE patients and healthy controls. However, the calculated $\chi^{2}$ value revealed that there is no significant difference in the allelic frequencies of the ACE gene between the SLE patients and healthy controls $\left(\chi^{2}=0.284, \mathrm{P}>0.05\right)$ (Table 1$)$. Thus, we postulated that there was no association between either of the alleles in the ACE gene I/D dimorphism to the susceptibility of SLE in Malaysian patients. This finding was further supported by another study carried out by Kaufman et al., in 2001, mainly in the African-American and European-American populations. However, contradictory results were also found in other studies. Sato and colleagues (1998) had revealed that the I allele was scored significantly higher in the Japanese SLE group compared to the healthy control group. A similar trend was observed in another Japanese-based study (Akai et al., 1999) and African-American families (Tassiulas et al., 1998). In contrast, the following year, Pullmann Jr. and co-workers (1999) had reported a statistically significant association between the D allele and SLE in the Slovakian population. Other groups have also postulated that it was the D allele that was the main cause (Harjacek et al., 1999; Prkacin et al., 2001).

Table 1. Allelic frequencies $(\mathrm{N}), \chi^{2}, \mathrm{P}$, odds ratio (OR), and $95 \% \mathrm{CI}$ (confidence interval) values of the ACE gene I/D dimorphisms in the Malaysian population.

\begin{tabular}{|c|c|c|c|c|}
\hline Allele & SLE patients [N (\%)] & Controls [N (\%)] & $\chi^{2}$ (P value) & OR $(95 \% \mathrm{CI})$ \\
\hline $\mathrm{I}$ & $223(65.6)$ & $242(63.2)$ & $0.284(0.5938)$ & $\begin{array}{c}1.0869 \\
(0.8002-1.4763)\end{array}$ \\
\hline $\mathrm{D}$ & $117(34.4)$ & $138(36.8)$ & & $\begin{array}{c}0.9201 \\
(0.6774-1.2498)\end{array}$ \\
\hline Total & $340(100)$ & $380(100)$ & & \\
\hline
\end{tabular}

SLE $=$ systemic lupus erythematosus.

Table 2. Genotypic frequencies $(\mathrm{N}), \chi^{2}$, P, odds ratio (OR), and 95\%CI (confidence interval) values of the ACE gene I/D polymorphisms in the Malaysian population.

\begin{tabular}{lcccc}
\hline Genotype & SLE patients [N (\%)] & Controls [N (\%) & $\chi^{2}$ (P value) & OR $(95 \% \mathrm{CI})$ \\
\hline II & $70(41.2)$ & $91(47.9)$ & $1.638(0.2006)$ & 0.7615 \\
DD & $17(10)$ & $39(20.5)$ & $7.568\left(0.0059^{*}\right)$ & $(0.5016-1.1561)$ \\
& & 0.4302 \\
ID & $83(48.8)$ & $60(31.6)$ & $11.143\left(0.0008^{*}\right)$ & $(0.2332-0.7937)$ \\
2.067 \\
Total & $170(100)$ & $190(100)$ & & $(1.3460-3.1743)$ \\
\hline
\end{tabular}

SLE $=$ systemic lupus erythematosus. ${ }^{*}$ Statistically significant. 
Curiously, the genotypic distribution of the ACE gene dimorphism was different between both the groups studied. The II homozygote and ID heterozygote are more frequent than the DD homozygote in the SLE patients. In contrast, the II homozygous state was more common if compared to the other two genotypes among the healthy controls (Table 2). Our current study has found that the presence of DD homozygote is significantly higher in the healthy control group, compared to the SLE patients $\left(\chi^{2}=7.568, \mathrm{P}<0.05\right)$. Similarly, another group of researchers had also reported a negative association between the DD homozygote and SLE among the AfricanAmerican patients (Tassiulas et al., 1998). However, in a meta-analysis carried out in 2006, consisting of 1411 patients with SLE and 1551 controls, Lee and colleagues (2006) observed a trend for association of the DD genotype $(\mathrm{OR}=1.212,95 \% \mathrm{CI}=0.966-1.520, \mathrm{P}=0.097)$ and the $\mathrm{D}$ allele with SLE in Caucasian patients $(\mathrm{OR}=1.157,95 \% \mathrm{CI}=0.991-1.349, \mathrm{P}=0.064)$; however, this was not statistically significant. However, analyses of 92 SLE patients showed that there was a significant association between DD genotypes and Raynaud's phenomenon $(\mathrm{OR}=5.4,95 \% \mathrm{CI}$ $=1.6-18.6, \mathrm{P}=0.008$ ) in a study in Kuwait SLE patients a year later (Al-Awadhi et al., 2007). Guan and co-researchers (1997) also found that the DD genotype was significantly higher in lupus nephritis $(\mathrm{LN})$ patients than in normal controls $(\mathrm{P}<0.01)$.

Based on our results, the ID heterozygote was significantly more frequent in SLE samples $\left(\chi^{2}\right.$ $=11.143, \mathrm{P}<0.05)$. Thus, we propose that the ID heterozygous state is significantly associated with the susceptibility of SLE, with respect to the Malaysian population. Furthermore, ID heterozygotes also show a higher level of disease penetration than the other two genotypes in SLE (OR = 2.067) (Table 2). This is in agreement with another study based on $144 \mathrm{LN}$ patients and 150 normal controls from China, were it was observed that patients with progressive renal function damage had a higher frequency of ID genotypes than those with stable renal function $(\mathrm{P}<0.01)$. The study concluded that in patients with LN the ID genotype was associated with the severity and the poor prognosis (Guan et al., 1997). Furthermore, according to Uhm et al. (2002), the ID genotype is associated with several established clinical manifestations and complications of SLE, i.e., hematuria, LN activation, severe tubulointerstitial and renal damages. Most of the individuals with ID heterozygous genotypes also possess anti-Sm antibodies in their serum, which is one of the criteria in confirming the diagnosis of SLE(Uhm et al., 2002). This supportive evidence has further authenticated our finding on the association of the ID heterozygote with SLE in the Malaysian population.

In general, ACE possesses a number of crucial roles in both RAS and kallikrein-kininogen system, which might be responsible for the vascular and nephrological disorders in SLE (Crisan and Carr, 2000; Joung et al., 2006; Duran-Barragan et al., 2008). Previous research has shown that the ACE gene I/D dimorphism could affect circulating ACE levels. The level of circulating ACE was found to be 2-fold higher in the individuals of the DD homozygous and lowest among the II homozygous genotypes (Kaufman et al., 2001). Likewise, Pullmann Jr. et al. (1999) had also discovered a significant association between the DD homozygotes and Slovakian SLE patients. This is contrasting with our current results as we postulate that the DD homozygous genotype might be protective to the development of SLE. In this context, the main reasons conferring these two distinct findings are the differences in the studied populations' genetic background as well as the geographical and environmental settings. Moreover, it is possible that 40 or more different genes may contribute to the susceptibility of SLE and these susceptibility genes differ among the various populations and thus present different gene-disease associations (Kaufman et al., 2001). In fact, if we compare ACE I/D dimorphism frequencies across different global populations alone, we can observe varied percentages (Table 3). Uniquely, only our popu- 
lation, as well as the Israeli population, showed an unusual distribution - while in most populations, the ID genotype is shown to be most common, the II genotype was the most frequently scored in our local population. The DD genotype accounted for more than half of the observed frequencies in Israel, notwithstanding their smaller sampling numbers.

\begin{tabular}{|c|c|c|c|c|c|}
\hline Population & Reference & $\mathrm{N}$ & II & ID & $\mathrm{DD}$ \\
\hline Turkish & Nacak et al., 2010 & 165 & 29.6 & 40.0 & 30.4 \\
\hline Brazilian & Sprovieri and Sens, 2005 & 65 & 12.3 & 60.0 & 27.7 \\
\hline African-American & Kaufman et al., 2001 & 129 & 16.3 & 48.1 & 35.6 \\
\hline Croatian & Prkacin et al., 2001 & 21 & 25.0 & 50.0 & 25.0 \\
\hline Korean & Uhm et al., 2002 & 114 & 34.0 & 50.0 & 16.0 \\
\hline Pakistani & Hussain et al., 2010 & 61 & 9.8 & 52.5 & 37.7 \\
\hline Pakistani & Rabbani et al., 2008 & 79 & 34.0 & 48.0 & 18.0 \\
\hline European-American & Kaufman et al., 2001 & 291 & 21.1 & 49.7 & 29.2 \\
\hline Israeli & Mold et al., 2000 & 48 & 15.0 & 31.0 & 54.0 \\
\hline Malaysian & This study & 190 & 47.9 & 31.6 & 20.5 \\
\hline
\end{tabular}

Data are reported in percentage.

In conclusion, all the alleles and genotypes of the ACE gene I/D dimorphism were scored among the Malaysian samples. Neither the I nor the D allele was associated with SLE. The DD homozygotes were found to be significantly associated with the healthy control group whereas the ID heterozygous genotype was significantly associated with the SLE patients. Therefore, we propose that this variation of ACE may not cause SLE directly in the Malaysian scenario, but may participate in the disease progression.

\section{ACKNOWLEDGMENTS}

Research supported by the University of Malaya research grants (\#RG117/09HTM and \#PS235/2010A).

\section{REFERENCES}

Akai Y, Sato H, Iwano M, Kurumatani N, et al. (1999). Association of an insertion polymorphism of angiotensinconverting enzyme gene with the activity of lupus nephritis. Clin. Nephrol. 51: 141-146.

Al-Awadhi AM, Haider MZ, Sharma PN, Hasan EA, et al. (2007). Angiotensin-converting enzyme gene polymorphism in Kuwaiti patients with systemic lupus erythematosus. Clin. Exp. Rheumatol. 25: 437-442.

Armitage P, Berry G and Matthews JNS (2002). Analysing Means and Proportions. In: Statistical Methods in Medical Research. 4th edn. Blackwell Science, UK.

Chew CH, Chua KH, Lian LH, Puah SM, et al. (2008). PCR-RFLP genotyping of C1q mutations and single nucleotide polymorphisms in Malaysian patients with systemic lupus erythematosus. Hum. Biol. 80: 83-93.

Chiang FT, Hsu KL, Chen WM, Tseng CD, et al. (1998). Determination of angiotensin-converting enzyme gene polymorphisms: stepdown PCR increases detection of heterozygotes. Clin. Chem. 44: 1353-1356.

Chua KH, Kee BP, Tan SY and Lian LH (2009a). Interleukin-6 promoter polymorphisms (-174 G/C) in Malaysian patients with systemic lupus erythematosus. Braz. J. Med. Biol. Res. 42: 551-555.

Chua KH, Lau TP, Tee ZY, Tan SY, et al. (2009b). Genetic polymorphisms of the interleukin-1 beta (IL-1 $\beta$ ) -511 and +3954 single nucleotide polymorphisms (SNPs) in Malaysian systemic lupus erythematosus (SLE) patients. $J$. Health Sci. 55: 657-662.

Chua KH, Hilmi I, Ng CC, Eng TL, et al. (2009c). Identification of NOD2/CARD15 mutations in Malaysian patients with Crohn's disease. J. Digest. Dis. 10: 124-130. 
Chua KH, Puah SM, Chew CH, Tan SY, et al. (2010). Study of the CTLA-4 gene polymorphisms in systemic lupus erythematosus (SLE) samples from Malaysia. Ann. Hum. Biol. 37: 275-281.

Crisan D and Carr J (2000). Angiotensin I-converting enzyme: genotype and disease associations. J. Mol. Diagn. 2: 105-115.

Duran-Barragan S, McGwin G Jr, Vila LM, Reveille JD, et al. (2008). Angiotensin-converting enzyme inhibitors delay the occurrence of renal involvement and are associated with a decreased risk of disease activity in patients with systemic lupus erythematosus - results from LUMINA (LIX): a multiethnic US cohort. Rheumatology 47: 1093-1096.

Guan T, Liu Z and Chen Z (1997). Angiotensin-converting enzyme gene polymorphism and the clinical pathological features and progression in lupus nephritis. Zhonghua Nei Ke Za Zhi 36: 461-464.

Harjacek M, Anic B and Bosnic D (1999). The role of genetic polymorphism of angiotensin-converting enzyme in lupus nephritis. Arthritis Rheum. 42: S302.

Hussain N, Jaffery G, Hasnain S and Anjum NS (2010). Angiotensin-converting enzyme gene I/D polymorphism in Pakistani systemic lupus erythematosus patients. Afric. J. Biotech. 9: 8134-8138.

Joung CI, Park YW, Kim SK, Uhm WS, et al. (2006). Angiotensin-converting enzyme gene insertion/deletion polymorphism in Korean patients with systemic sclerosis. J. Korean Med. Sci. 21: 329-332.

Kaufman KM, Kelly J, Gray-McGuire C, Asundi N, et al. (2001). Linkage analysis of angiotensin-converting enzyme (ACE) insertion/deletion polymorphism and systemic lupus erythematosus. Mol. Cell Endocrinol. 177: 81-85.

Kim DS, Choi SI, Lee HS, Park JK, et al. (2001). Determination of human angiotensin converting enzyme (ACE) gene polymorphisms in erectile dysfunction: frequency differences of ACE gene polymorphisms according to the method of analysis. Clin. Chem. Lab. Med. 39: 11-14.

Kumar V, Abbas AK, Fausto N and Mitchell RN (2007). Robbins Basic Pathology. 8th edn. Saunders, Philadelphia.

Lee YH, Rho YH, Choi SJ, Ji JD, et al. (2006). Angiotensin-converting enzyme insertion/deletion polymorphism and systemic lupus erythematosus: a metaanalysis. J. Rheumatol. 33: 698-702.

Lian LH, BP Kee, HL Ng and Chua KH (2011). Lack of association between RANTES-28, SDF-1 gene polymorphisms and systemic lupus erythematosus in the Malaysian population. Genet. Mol. Res. 10: 2841-2850.

McPherson G (2001). Applying and Interpreting Statistic: A Comprehensive Guide. 2nd edn. Springer, New York.

Mold Y, Gal E, Magal N, Sulkes J, et al. (2000). Renal outcome and vascular morbidity in systemic lupus erythematosus (SLE): lack of association with the angiotensin-converting enzyme gene polymorphism. Semin. Arthritis Rheum. 30: 132-137.

Nacak M, Nacak I, Sanli M, Ozkur, et al. (2010). Association of angiontensin-converting enzyme gene insetion/deletion polymorphism with lung cancer in Turkey. Cancer Genet. Cytogenet. 198: 22-26.

Pfohl M, Koch M, Prescod S, Haase KK, et al. (1999). Angiotensin I-converting enzyme gene polymorphism, coronary artery disease and myocardial infarction. An angiographically controlled study. Eur. Heart J. 20: 1318-1325.

Prkacin I, Novak B, Sertic J and Mrzljak A (2001). Angiotensin-converting enzyme gene polymorphism in patients with systemic lupus. Acta Med. Croatica 55: 73-76.

Puah SM, Lian LH, Chew CH, Chua KH, et al. (2007). A study of association of the complement C4 mutations with systemic lupus erythematosus in the Malaysian population. Lupus 16: 750-754.

Pullmann R Jr, Lukac J, Skerenova M, Rovensky J, et al. (1999). Association between systemic lupus erythematosus and insertion/deletion polymorphism of the angiotensin converting enzyme (ACE) gene. Clin. Exp. Rheumatol. 17: 593-596.

Rabbani MA, Mahmood MS, Mekan SF and Frossard PM (2008). Association of angiotensin-converting enzyme gene dimorphisms with severity of lupus disease. Saudi J. Kidney Dis. Transpl. 19: 761-766.

Rigat B, Hubert C, Corvol P and Soubrier F (1992). PCR detection of the insertion/deletion polymorphism of the human angiotensin converting enzyme gene (DCP1) (dipeptidyl carbozypeptidase 1). Nucleic Acids Res. 20: 1433.

Sato H, Akai Y, Iwano M, Kurumatani N, et al. (1998). Association of an insertion polymorphism of angiotensinconverting enzyme gene with the activity of systemic lupus erythematosus. Lupus 7: 530-534.

Shanmugam V, Sell KW and Saha BK (1993). Mistyping ACE heterozygotes. PCR Methods Appl. 3: 120-121.

Sprovieri SR and Sens YA (2005). Polymorphisms of the renin-angiotensin system genes in Brazilian patients with lupus nephropathy. Lupus 14: 356-362.

Tan EM, Cohen AS, Fries JF, Masi AT, et al. (1982). The 1982 revised criteria for the classification of systemic lupus erythematosus. Arthritis Rheum. 25: 1271-1277.

Tassiulas IO, Aksentijevich I, Salmon JE, Kim Y, et al. (1998). Angiotensin I converting enzyme gene polymorphisms in systemic lupus erythematosus: decreased prevalence of DD genotype in African American patients. Clin. Nephrol. 50: 8-13.

Teh CSJ, Chua KH and Thong KL (2010). Simultaneous differentiation detection of human pathogenic and nonpathogenic Vibrio species using a multiplex PCR based on gryB and pntA gene. J. Appl. Microbiol. 108: 1940-1945.

Thong KL, Lai MY, Teh CS and Chua KH (2011). Simultaneous detection of methicillin-resistant Staphylococcus aureus, Acinetobacter baumannii, Escherichia coli, Klebsiella pneumoniae and Pseudomonas aeruginosa by multiplex PCR. Trop. Biomed. 28: 21-31. 
Uhm WS, Lee HS, Chung YH, Kim TH, et al. (2002). Angiotensin-converting enzyme gene polymorphism and vascular manifestations in Korean patients with SLE. Lupus 11: 227-233.

Wallace DJ and Hahn BH (1997). Dubois' Lupus Erythematosus. 5th edn. Williams and Wilkins, Philadelphia.

Wang F, Wang CL, Tan CT and Manivasagar M (1997). Systemic lupus erythematosus in Malaysia: a study of 539 patients and comparison of prevalence and disease expression in different racial and gender groups. Lupus 6: 248-253. 